\title{
On the Perception of Illusory Contours
}

\author{
V. S. RAMACHANDRAN, ${ }^{*}$ D. RUSKIN,${ }^{*}$ S. COBB,${ }^{*}$ D. ROGERS-RAMACHANDRAN, ${ }^{*}$ \\ C. W. TYLER† \\ Received 5 August 1993; in revised form 23 February 1994
}

\begin{abstract}
Illusory contours are invoked by the visual system to account for otherwise inexplicable gaps in the image. We report three sets of novel observations on illusory contours. First, when an illusory square is superimposed on a checkerboard pattern there is a considerable enhancement of the contours so long as they are exactly coincident with the borders of the checks. If the checks are misaligned, on the other hand, the illusory contours associated with the pacman edges disappear and a novel percept emerges: the contours of the checks nearest to the illusory square appear enhanced. This result implies that subjective contours are generated by intermediate-level contour interactions rather than the topdown processes of three-dimensional interpretation. Second, we find that steady fixation for as little as 4 sec leads to a complete disappearance of the enhanced illusory contours caused, presumably, by adaptation or "fatigue" of cells that signal these contours. Such adaptation occurred even when the illusory contours were rendered invisible by displaying them on a misaligned checkerboard, suggesting that the adaptation occurs prior to the vetoing of the signal by the checks. Third, we found that illusory contours persist for a surprisingly long time $(0.3 \mathrm{sec})$ after the inducing elements have been switched off. These results suggest that the stimuli we have designed ("enhanced illusory contours") might provide a novel probe for dissecting different stages involved in the processing of illusory contours and for understanding how the visual system combines different types of contours to construct object boundaries.
\end{abstract}

Illusory contours Segmentation Adaptation Visual persistence

\section{INTRODUCTION}

Figure 1 shows a square defined by illusory contours (Brady \& Grimson, 1981; Coren, 1972; Gregory, 1972; Prazdny, 1985; Francis, 1994; Kanizsa, 1976; Rock, 1983; Schumann, 1904; Kellman \& Loukides, 1987). Such contours can be produced by appropriately aligned black disks from which right-angle sectors have been removed. The brain interprets this figure parsimoniously as an opaque white square with its four corners occluding the four black disks (and not as four sectored disks that have been deceitfully aligned by the experimenter). One has the enigmatic impression of a contour connecting these aligned edges, even though no contour exists physically-hence the name "illusory contours".

Whether these contours are physical, physiological, or truly "subjective" is a much debated semantic issue that need not concern us here. Whatever their epistemological implications, illusory contours provide a compelling demonstration of the principle that a great deal of tacit knowledge about the statistics of the natural world must be built into early visual processing. Collinear edges

*Neurosciences Program and Psychology Department 0109, University of California-San Diego, 9500 Gilman Drive, La Jolla, CA 92093-0109, U.S.A. [Fax (619) 534-7190].

$†$ Smith-Kettlewell Eye Research Institute, 2232 Webster Street, San Francisco, CA 94115, U.S.A convey an impression of occlusion because through millions of years of trial and error the brain has learned that collinear edges are usually produced by occluding objects.

Illusory contours are probably extracted fairly early in visual processing (von der Heydt, Peterhans \& Baumgartner, 1985) and they are also known to powerfully constrain a number of "front-end" visual processes, such as stereo correspondence (Ramachandran, 1986), motion correspondence (Ramachandran, 1985), and shape from shading (Ramachandran, 1988). Indeed, many of these illusions (e.g. motion capture) are more strongly influenced by illusory contours than by real luminance edges, an observation which leads to the paradoxical conclusion that, as far as the early visual system is concerned, "illusory contours are more real than real contours" (Ramachandran, 1992). The paradox is resolved once you realize that the goal of vision is to delineate object boundaries-not merely to respond to edges. And although object boundaries are often associated with luminance edges, such edges can also arise from a number of other spurious sources-e.g. the edges of cast shadows, reflectance edges, etc. Illusory contours, on the other hand, are always associated with the configuration for occlusion, which, in turn, is always diagnostic of a true object boundary. Remarkably, the early visual system seems to "know" this rule. 

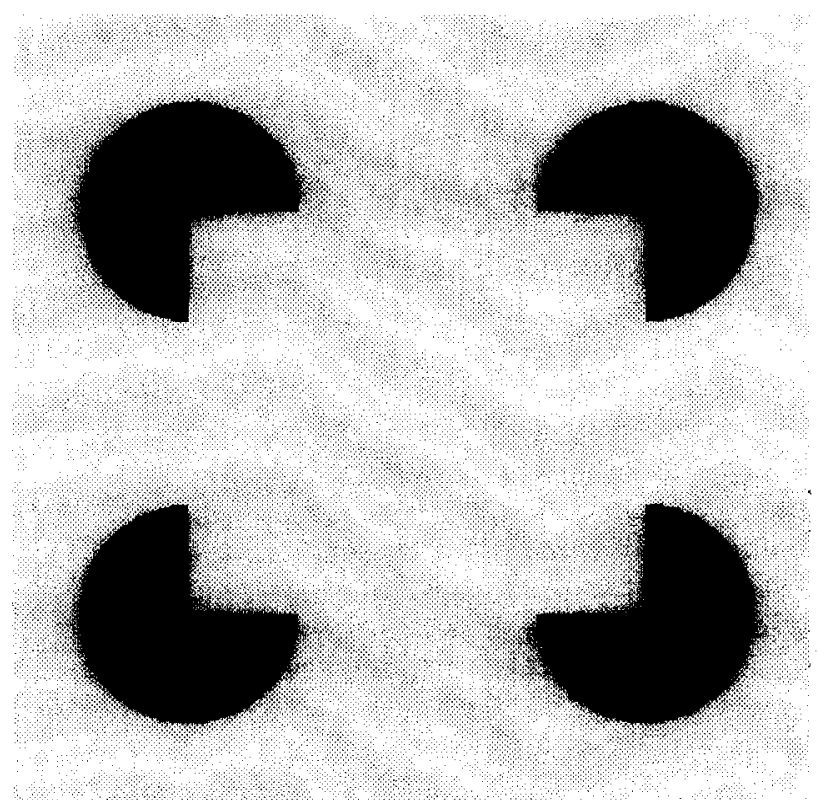

FIGURE 1. An example of an illusory square produced by removing pie-shaped wedges from four black disks.

Some preliminary observations suggested that illusory contours could be enhanced considerably by superimposing them on a checkerboard pattern (Fig. 2) so that the edges of the pacmen are lined up with the edges of the checks (Ramachandran, 1986). We found that it was easier to make perceptual judgments on those "enhanced" illusory contours than on the more usual Kanizsa-type figures, i.e. subjects found it easier to rate the subjective vividness of the contour. Using these enhanced illusory contours as a probe, we tried to answer the following three questions. (1) How do illusory contours interact with "real" luminance edges in

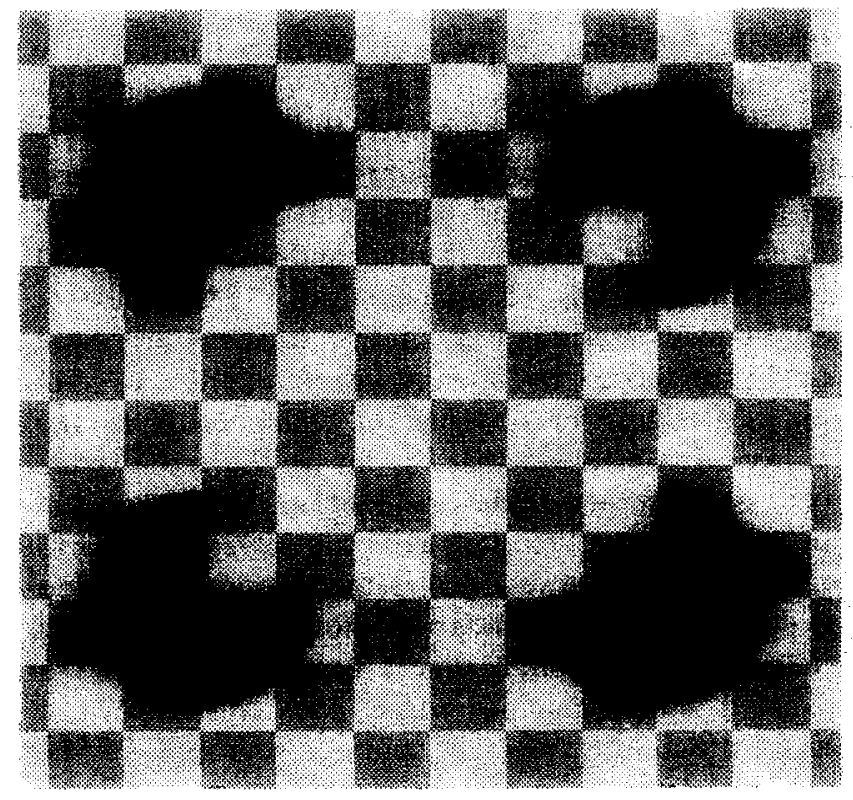

FIGURE 2. A vivid enhancement of illusory contours is seen when the square is superimposed on a low-contrast checkerboard pattern. The effect is much more compelling when viewed directly on the CRT. the vicinity? (2) Would it be possible to adapt selectively to illusory contours? If so, what is the time course of this adaptation? (3) How long do illusory contours persist after the inducing elements have been switched off?

\section{EXPERIMENT 1: CONTOUR INTERACTIONS}

In our first experiment we began by simply superimposing an illusory square on a checkerboard pattern (Fig. 2). We found that this produced a striking enhancement of the illusory contours and a vivid impression of a square piece of checkerboard partially occluding four black disks in the background (Ramachandran, 1986, 1992). The enhancement is seen only when the edges of the checks are collinear with the edges of the "pacmen". If checks were deliberately misaligned the illusory contours associated with the pacmen vanished, but we found that a novel percept emerged: subjects noticed an enhancement of the borders of the checks that were nearest to the original illusory contour so that a new illusory square emerged (Fig. 3).

This observation implies that the reason for the failure to see subjective contours in Fig. 3 is that they are blocked or inhibited by the orthogonal real contours in their path. However, the facilitation of nearby checkerboard contours of the same orientation implies cooperative interactions between parallel adjacent subjective contours. This kind of contour interaction seems to be occurring at a more primitive level than the top-down process of "making sense" of the information presented in terms of a three-dimensional interpretation, since generation of the illusory square in Fig. 3 does not resolve the contradiction of the four pacman shapes, each of which seems to be occluded locally by the corner of an invisible object.

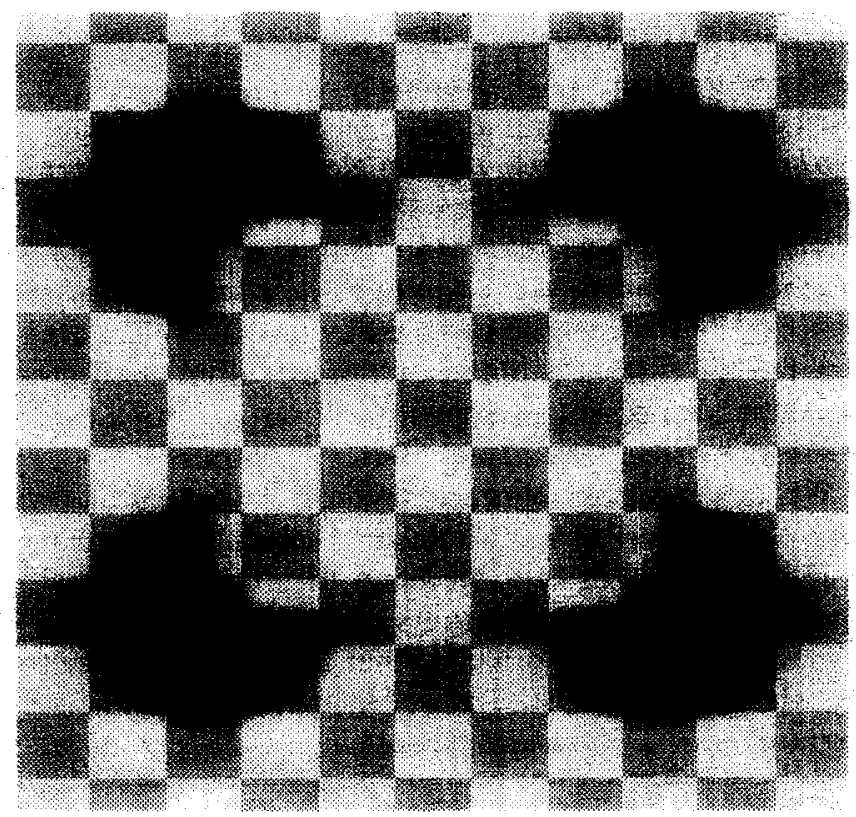

FIGURE 3. The illusory contours associated with the pacman edges disappear completely, but most observers report a novel percept: a smaller illusory square that is concentric with the original and corresponds to the nearest subset of checks. 
We attempted some informal measurements of the strength of these illusions by presenting the three figures (Figs 1-3) to naive subjects side-by-side for comparison and asking them to rate the strength of the illusory figure on a subjective scale of $1-10$. They were asked to move their eyes around the display to prevent perceptual fading (see Expt 4). The mean rating for eight subjects (one trial each) was 3.3 (checks out of phase), 5.6 (no checks), and 8.6 (checks in phase). Thus the presence of checks in the background clearly influences the perception of the illusory figure. It is easy to see why misaligned checks should reduce the vividness of the illusory figure since, as suggested by Reynolds (1981), the image is no longer compatible with the percept of an opaque square "occluding" the disks in the background. The enhancement that we observed when the illusory contours and the checks are aligned, however, is difficult to explain. After all, adding the checks docs not provide any extra information that is consistent with occlusion, since there is, in fact, an astronomical number of potential squares associated with the checkerboard. Yet the illusory figure seems to "highlight" the appropriate square. The observation implies that when different types of contours are coincident spatially, they enhance each other so as to
(A)

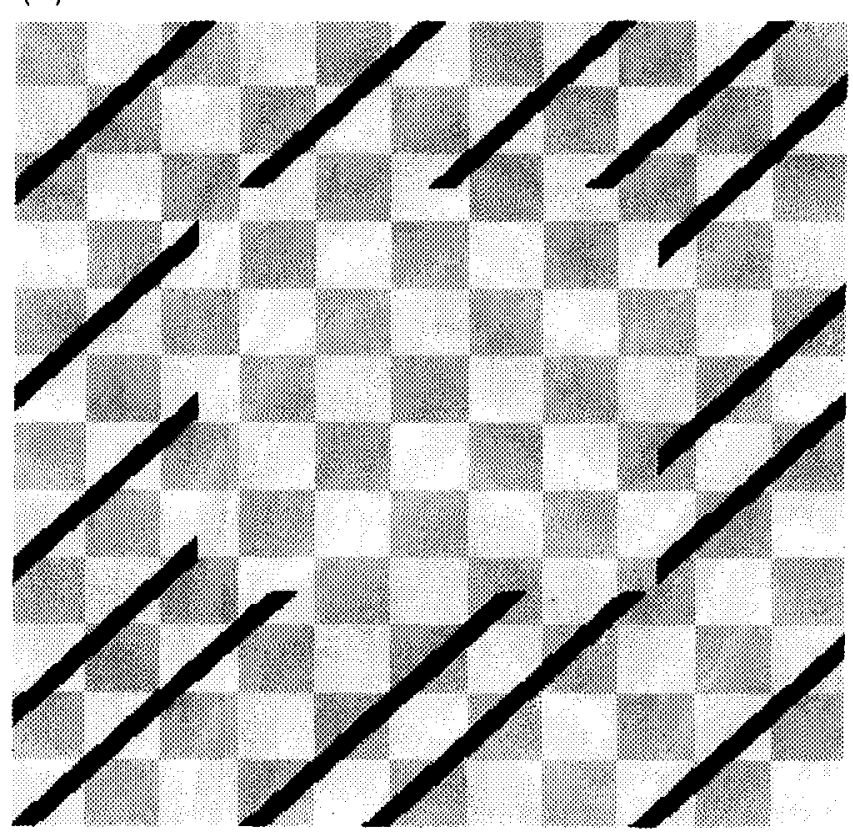

(C)

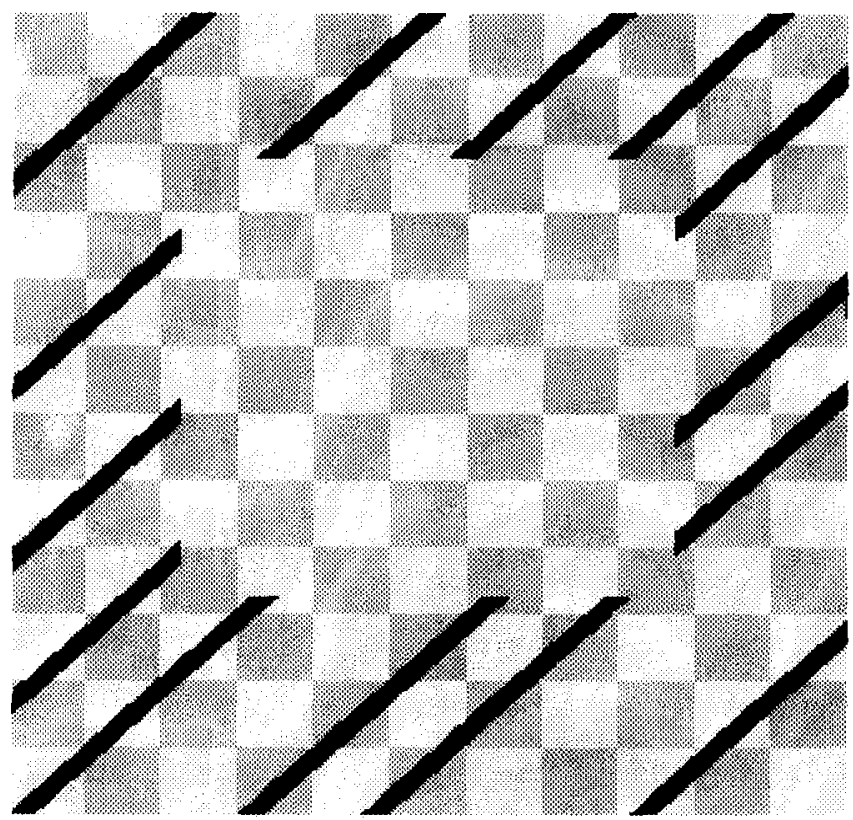

(B)

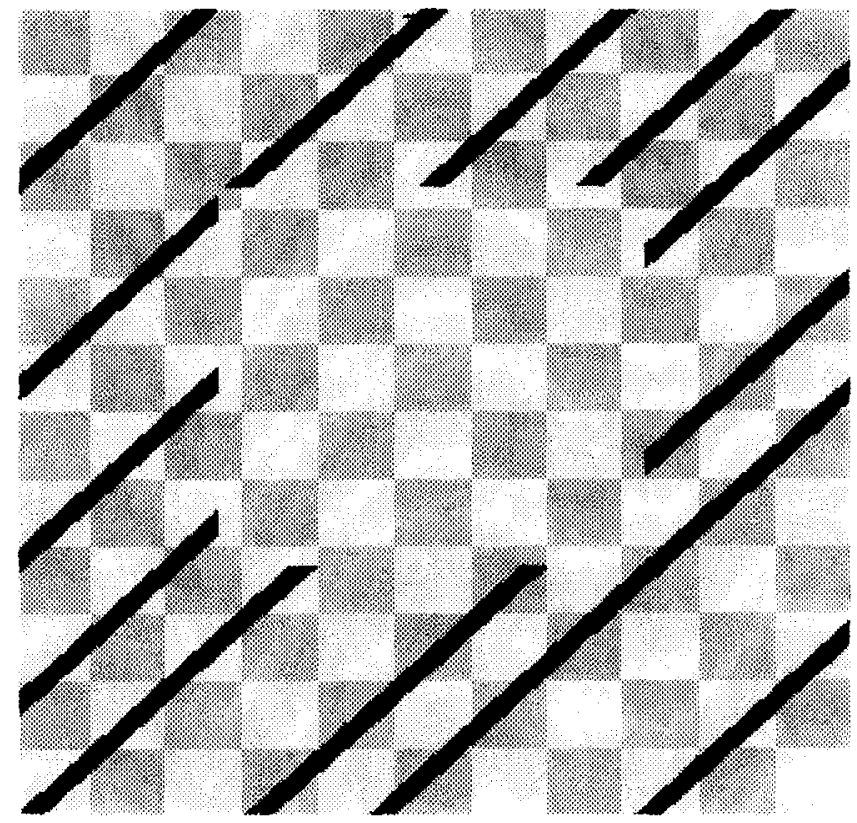

(D)

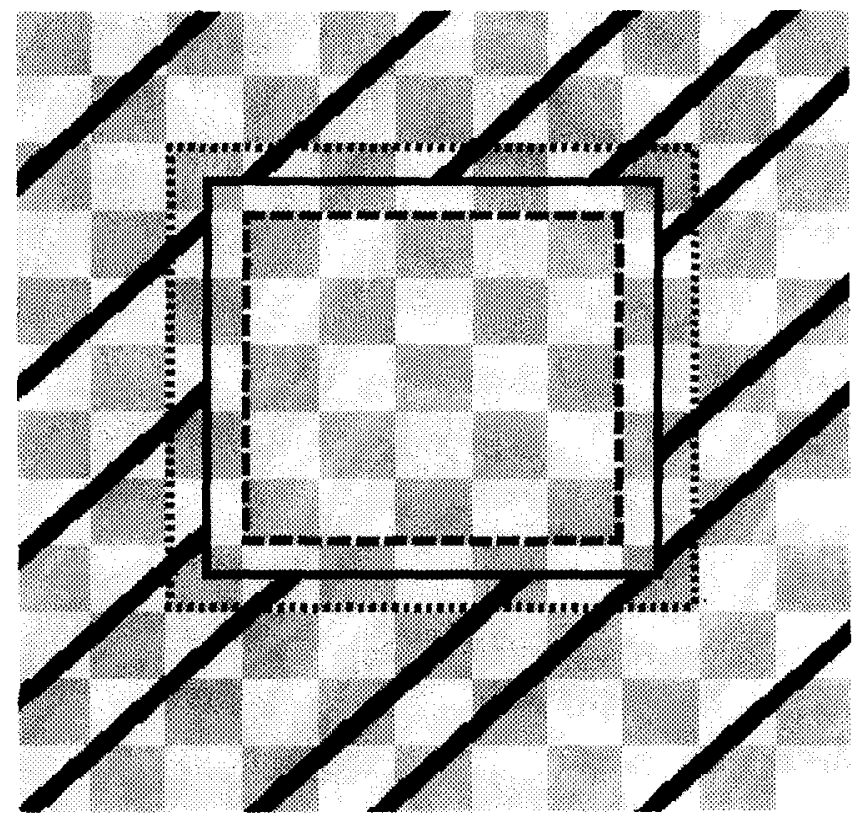

FIGURE 4. The enhancement effect depends partly on the distance between the illusory contours and the checks. Compare (A), (B), and (C). In (D), area 1 is depicted schematically by the solid outlined square, area 2 by the inner dashed outline, and area 3 by the outer dotted outline square. Subjects generally perceive an enhanced inner square (area 2) in (B) and an enhanced outer square (area 3$)$ in $(\mathrm{C})$ 
increase the subjective certainty that there is a true object boundary associated with those contours. This may be one strategy used by the visual system to decide whether a given contour represents a true object boundary or whether it is merely a reflectance edge or a cast shadow.

\section{EXPERIMENT 2: ENHANCEMENT OF ADJACENT LUMINANCE EDGES}

A novel percept was obtained using displays such as Fig. 4. Notice that in these displays there is no illusory contour coincident with the tips of the sloping lines but that a new illusory square emerges whose edges correspond to the borders of the checks that are close to line tips. Moreover, there is also a slightly greater tendency to see the square that is immediately inside the tips as more vivid than the one immediately outside the line tips.

To measure these effects we created three displays [Fig. $4(\mathrm{~A}, \mathrm{~B}, \mathrm{C})]$ in which the distance between the line tips and adjacent luminance edges was varied. In Fig. 4(C) the tips were closest to the border that was immediately outside whereas in Fig. 4(B) the tips were nearest to the borders of the checks that were inside. Subjects were then asked to compare the strength of the illusory contour (if any) associated with three areas (1-3) corresponding to either the original illusory contour defined by the line tips [area 1 in Fig. 4(D)]; the illusory square formed by the edges of the checks just within the area defined by the line tips [area 2 in Fig. 4(D)]; or the imaginary square formed by the edges of checks just outside the area defined by the line tips [area 3 in Fig. 4(D)].

Area 1 received very low ratings (1.5) by all subjects. For areas 2 and 3 in Fig. 4(D), the ratings were inversely proportional to the distances between the imaginary square in question and the tips of the lines, i.e. the enhancement of the border of the checks was greater when the tips were close to them (Fig. 5).

In addition to this obvious distance effect, there was also a greater tendency to see the "inside" square as more vividly enhanced than the other one implying that the percepts generated by these contour interactions are also sensitive to certain topological "figure-ground" characteristics such as inside vs outside or occlusion from the overlaid black lines.

\section{EXPERIMENT 3: PERSISTENCE OF ILLUSORY CONTOURS}

Intriguingly, we found that when we switched off the inducing elements in Fig. 6(A) or (C) the illusory square persisted for a short while even though the inducing elements were no longer visible. To study this more carefully we designed a three-frame display [Fig. 6(A, B, C)] in which the inducing stimuli were preset only in frames 1 and 3 , and there were no inducing elements in frame 2. The duration of the three frames could be varied continuously by the subject and his task was to adjust the duration so that the illusory square was continuously visible (both ascending and descending readings were obtained). Using this procedure we found that the illusory figure remained visible for at least $310 \mathrm{msec}$ after the inducing elements had been switched off (mean $=$ $340 \mathrm{msec}$; $\mathrm{SD}=108 \mathrm{msec} ; n=10$ subjects).

The remarkable persistence of illusory contours is reminiscent of the persistence of Cyclopean figures in random-dot stereograms when one eye's image is temporarily switched off (Ramachandran, 1974). Again, by simply flickering one eye's image at a very low rate (e.g. $0.5-3 \mathrm{~Hz}$ ) we were able to determine that the cyclopean figure can persist for as long as $0.5 \mathrm{sec}$ when one eye's image is switched off. Interestingly, no such effect is seen if both eyes' images are switched off simultaneously. The cyclopean figure then disappears instantly along with the dots.

\section{EXPERIMENT 4: ADAPTATION TO ILLUSORY CONTOURS}

We also found that illusory figures tend to fade relatively quickly on steady fixation. Such fading also

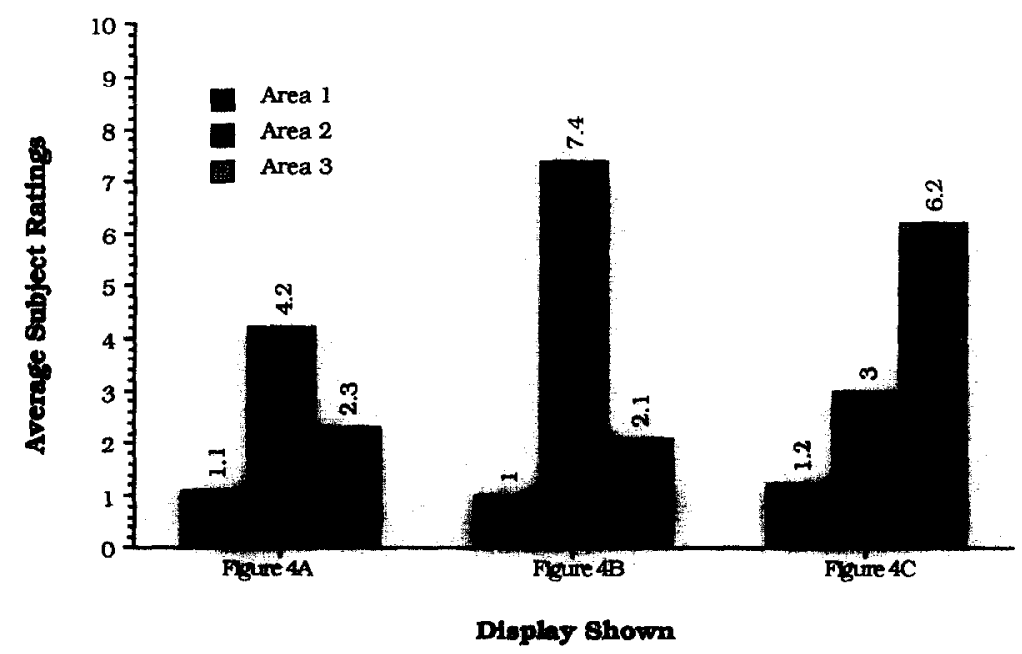

FIGURE 5. Relative strengths of the enhanced illusory contours seen in Fig. 4 (A, B, C). 
(A)

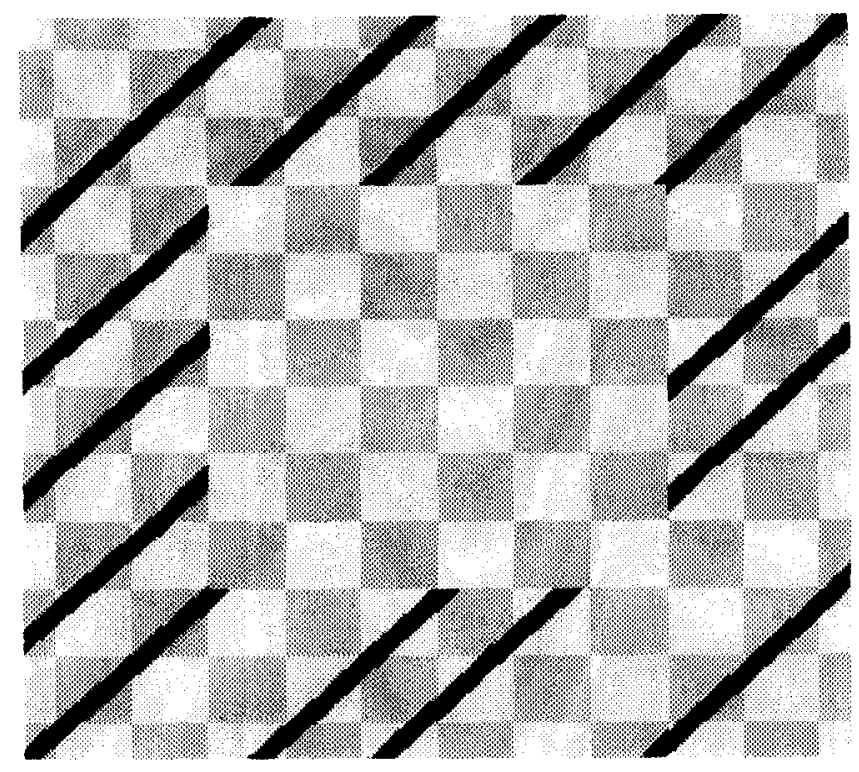

(B)

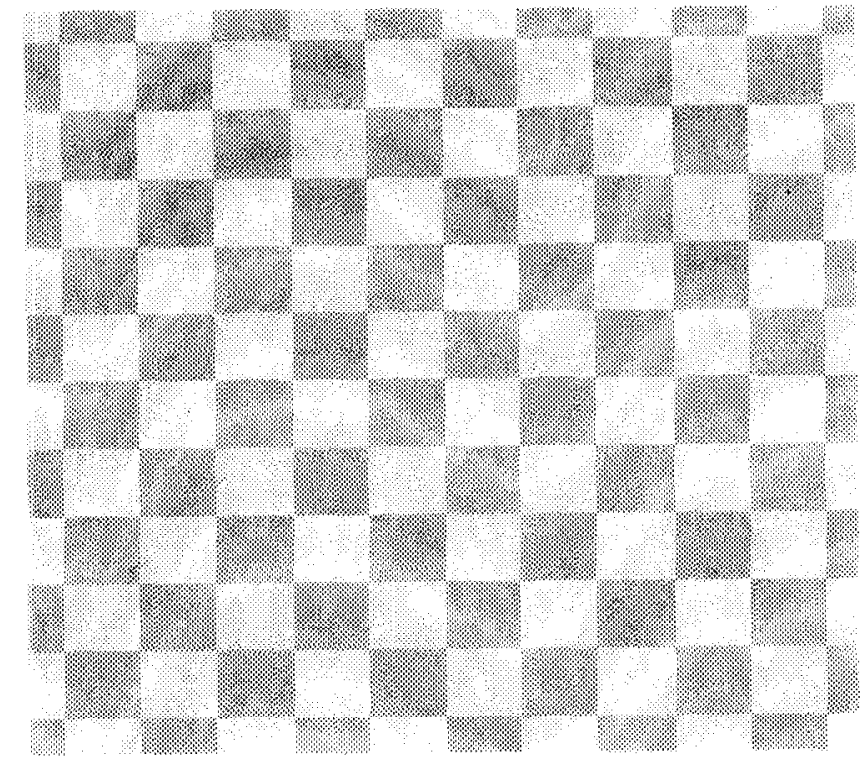

(C)

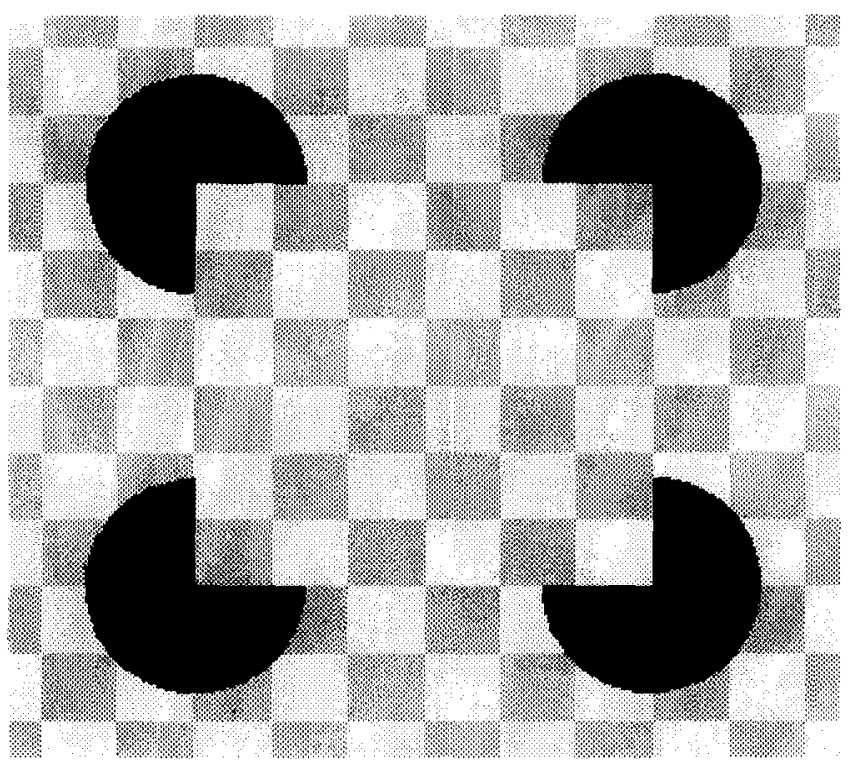

FIGURE 6. Depicts the three-frame sequence $(\mathrm{A} \rightarrow \mathrm{B} \rightarrow \mathrm{C})$ that was used to test the persistence of enhanced illusory contours.

occurs for conventional Kanizsa-type figures, as first shown by Livingstone and Hubel (1987), but we found the effect to be especially strong when we use "enhanced illusory contours" such as Fig. 2. To measure this effect, we simply had subjects fixate a small red spot on the CRT and then switched on Fig. 7 (Fig. 2 with a fixation dot) while the subjects continued to fixate on the spot. Their task was to press a computer keyboard as soon as the illusory contour disappeared on each trial. Using this procedure we found that, on average, the square took about $4 \mathrm{sec}$ to fade completely (mean $=4.6 \mathrm{sec}$; $\mathrm{SD}=2.3 \mathrm{sec} ; n=12$ subjects)

Next, we wondered whether the adaptation depends only on the illusory figure or also on the inducing elements. For example, if one were to adapt to an illusory square defined by lines tilted $45 \mathrm{deg}$ to the left would the adaptation transfer to an identical square defined by lines tilted to the right? To answer this question, we displayed Fig. 8(A) on the monitor and the subject was instructed to fixate steadily on a red spot on the screen until the illusory contours faded. The subject then had to press a computer key while continuing to fixate on the red dot. This changed the display from Fig. 8(A) to (B). The subject's task was to simply report whether or not the illusory contours continued to remain invisible or whether it reappeared when the new display was switched on. Two trials were run for each of eight subjects and the results were recorded by the experimenter.

We found that on $92 \%$ of the trials, subjects reported that the illusory square quickly reappeared when the stimulus was changed. Many subjects noticed, however, that the square became transiently invisible and appeared to "flicker" before emerging again. 


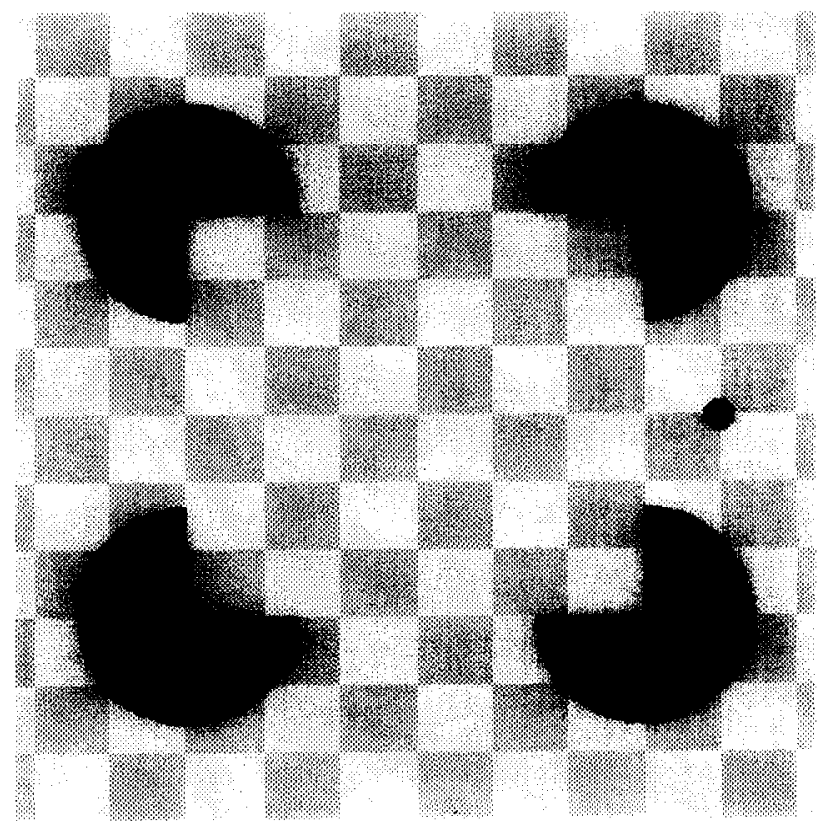

FIGURE 7. Adaptation to illusory contours. Steadily fixate on the dot. The illusory square will fade in a few seconds.

\section{EXPERIMENT 5: ADAPTATION TO INVISIBLE ILLUSORY CONTOURS}

We noted earlier that the illusory figure becomes invisible when it is superimposed on background checks whose edges are misaligned with the illusory contours. The most parsimonious interpretation of this would be that the illusory contours are signaled by a set of nerve cells early in visual processing (e.g. V2, von der Heydt et al., 1984) but that this signal is subsequently "vetoed" by the checks at some higher level. If so, one could ask whether the adaptation to illusory contours occurs before or after this vetoing. In other words, would it be possiblc to adapt to contours that one does not actually perceive? To explore this, we used a two-frame stimulus sequence in which Fig. 9(A) (Fig. 3 with fixation dot) appeared in frame 1 followed by Fig. 9(B) (Fig. 2 with dot) in frame 2. While fixating a small red spot that was off to one side, we found that if frame I was flashed on very briefly (e.g. $50 \mathrm{msec}$ ) and followed by frame 2 , subjects had no difficulty in seeing the illusory figure in frame 2. However, if frame 1 was displayed for a second or more and followed by frame 2 , the illusory figure in frame 2 took several seconds to emerge (Ramachandran. Tyler \& Rogers-Ramachandran, 1992)!

A more formal experiment along these lines was carried out on 11 subjects. Each subject was asked to focus on a small red dot that was superimposed on the right side of a checkerboard display that did not contain any inducing elements. On each of 32 successive trials, Fig. 9(A) was flashed for a variable time $T$. On each trial, Fig. 9(A) was followed immediately by Fig. 9(B), the illusory contour figure (the red dot remained visible throughout). The subject fixated the red dot at all times and his task was to record precisely when the illusory contours of the second figure, Fig. 9(B), became clearly visible. The subject recorded his response by pressing a computer key. On different trials, Fig. 9(A) was presented for one of several durations as follows: $T=33$, $66,100,133,166,250,333,416,500,666,833,1000$,
(A)

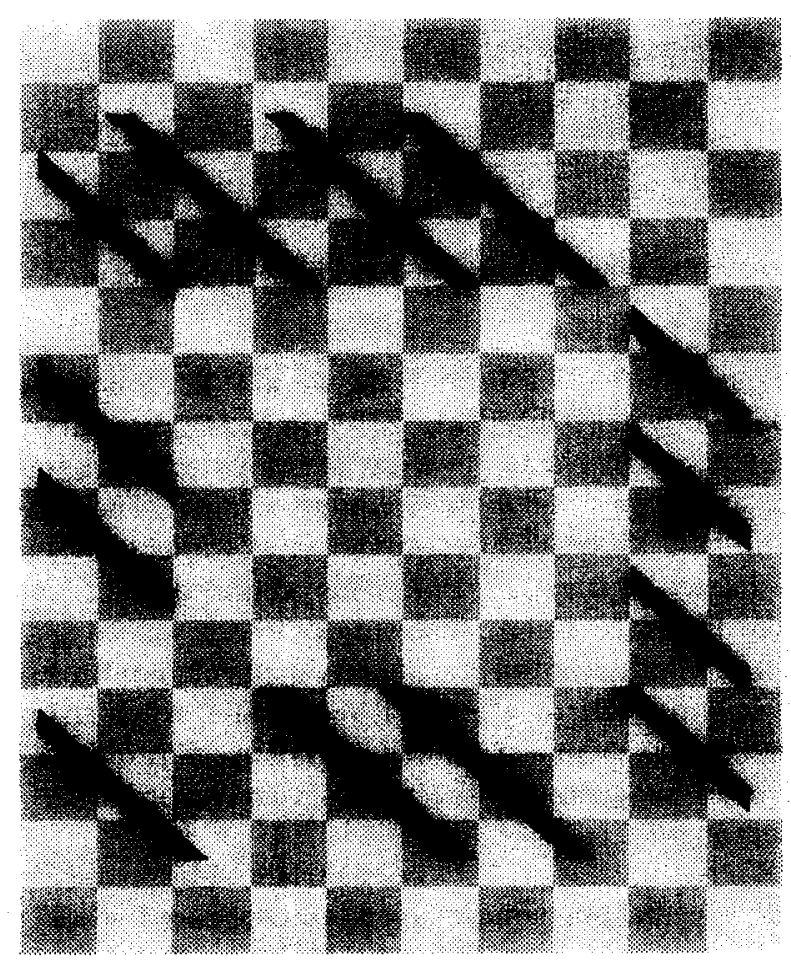

(B)

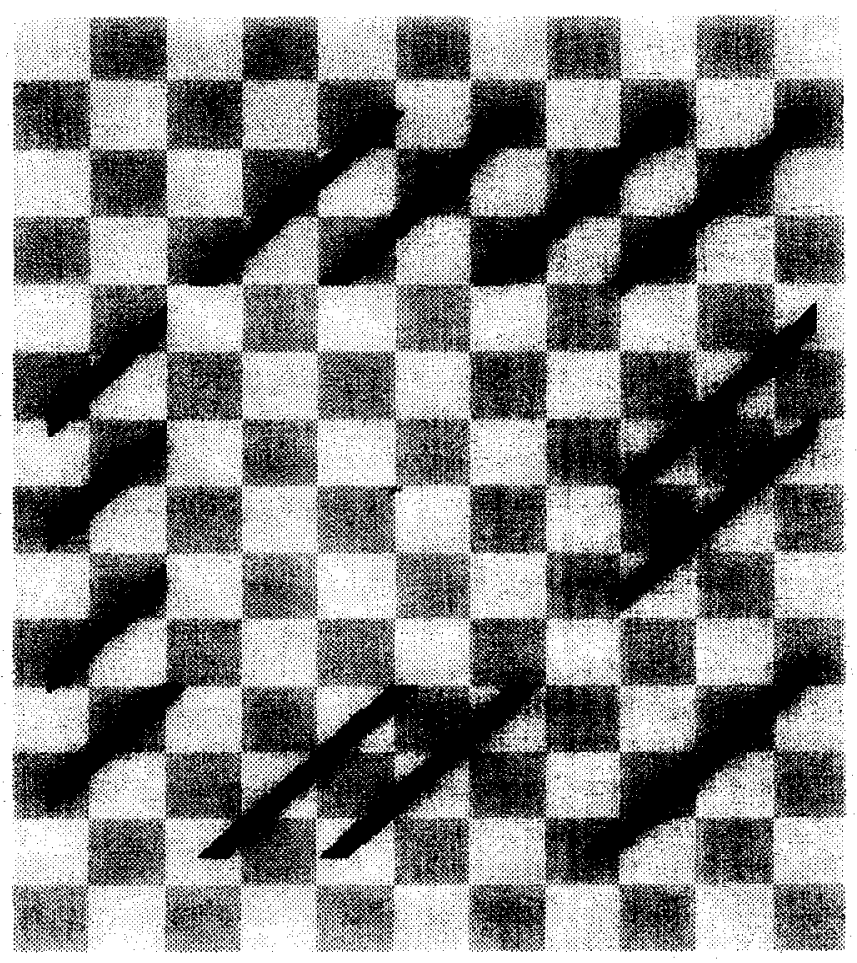

FIGURE 8. Two-frame sequence $(\mathrm{A} \rightarrow \mathrm{B})$ used to demonstrate that the adaptation involves not only the illusory contours. but surprisingly, the induced elements as well. 
(A)

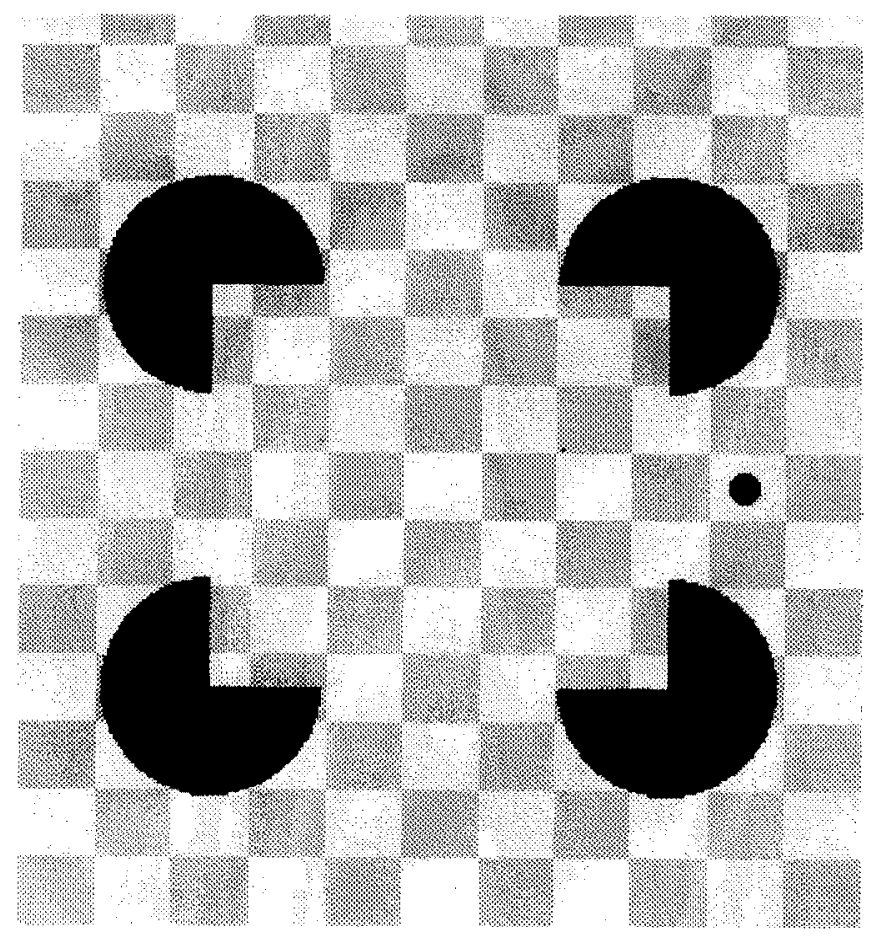

(B)

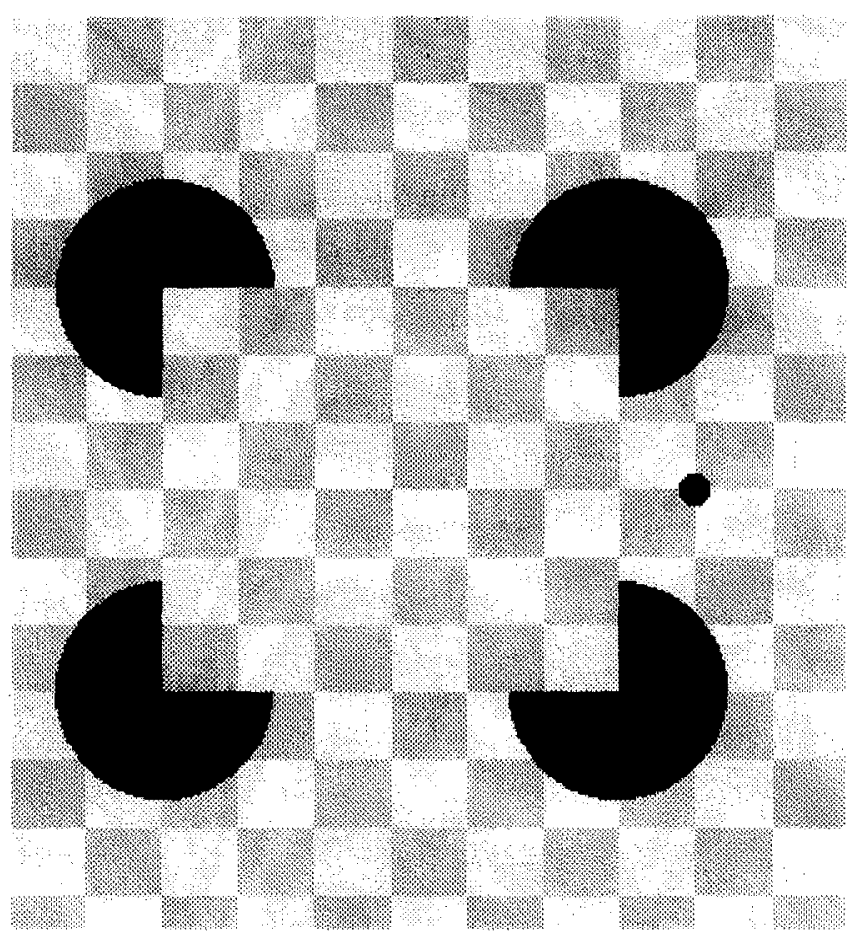

FIGURE 9. Utilizes the same display as Figs 2 and 3, presented in the sequence $(A \rightarrow B)$, to show that the visual system can adapt to the illusory contours that are not consciously visible.

$1500,2000,2500$, and $3000 \mathrm{msec}$. Each time $T$ was used on two of the trials. All trials were displayed in a random order.

The results were clear-cut (Fig. 10). Response times increased monotonically with increasing display times of Fig. 9(A). Thus, adaptation to invisible contours [Fig. $9(\mathrm{~A})]$ prevents the perception of illusory contours in Fig. 9(B).

One interpretation of these findings would be that prior exposure to frame 1 for a second or more leads to adaptation to the illusory contours so that no figure is seen in frame 2 until enough time $(>2 \mathrm{sec}$ ) has elapsed to allow recovery from adaptation. If this interpretation is correct, then the implication would be that one can adapt to illusory contours even when they are invisible! We suggest that the adaptation occurs in V2 where there are cells that respond to illusory edges (von der Heydt et al., 1984) and that the "vetoing" by the checks occurs at some subsequent stage in processing.

In summary, we find that (a) illusory figures are enhanced considerably if they are superimposed on a checkerboard pattern so that the edges of the checks coincide with the illusory edges; (b) "real" contours can inhibit illusory contours in the vicinity; (c) illusory contours can persist for as long as $0.3 \mathrm{sec}$ after the inducing elements have been switched off; and (d) one

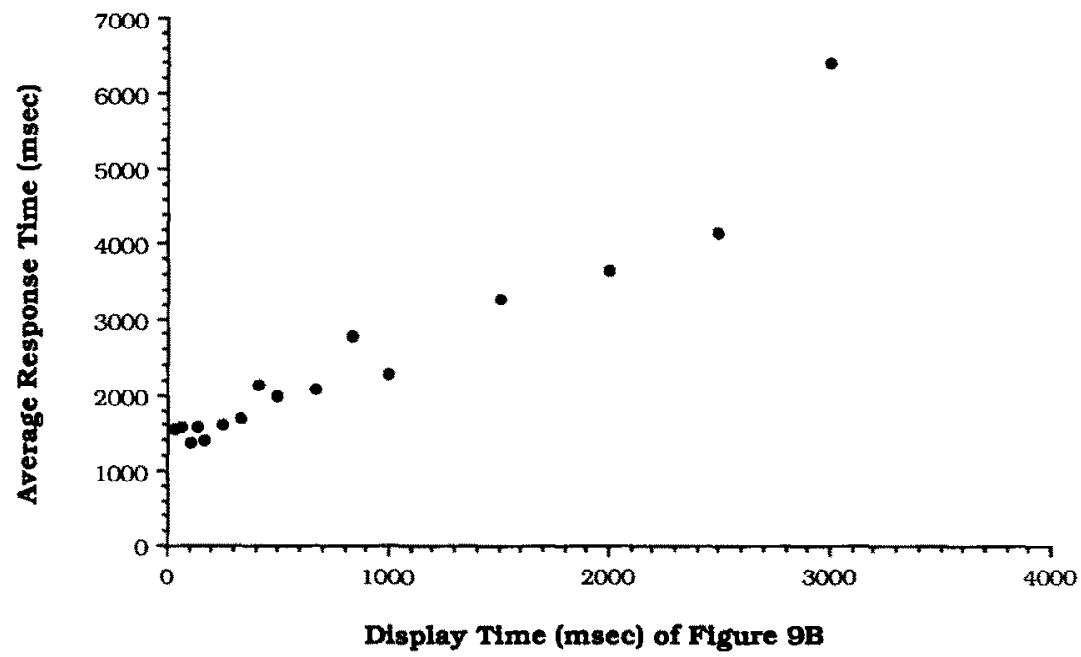

FIGURE 10. Depicts the manner in which exposure to an invisible illusory square can lead to a reduction in the visibility of a subsequently presented illusory square that would normally be strongly visible (without prior adaptation). 
can "adapt" to illusory figures even when the figure is rendered invisible by misaligned checks in the background. This implies that the adaptation occurs before the illusory figure is "vetoed" by the checks.

Our stimuli also lend themselves readily to some simple physiological experiments. For cxample, certain cells in V2 are known to respond vigorously to illusory contours. Would the responses of these cells persist for as long as $0.3 \mathrm{sec}$ ? And can the response of the cell be modulated by having checks "in phase" or out of phase in the background? Such experiments may tell us whether these interactions are based on the numerous reciprocal connections (Van Essen, 1985) that exist between different visual areas connections whose functions have long remained mysterious.

\section{REFERENCES}

Brady, M. \& Grimson, W. E. (1981). The perception of subjective surfaces. MIT (al Memo No. 666). Cambridge, Mass.: Massachusetts Institute of Technology.

Coren, S. (1972). Subjective contours and apparent depth. Physchological Review, 79, 359-367.

Finkel, L. H. \& Sajla, P. (1994). Constructing visual perception. American Scientist, 82, 224-237.

Francis, G., Grossberg, S. \& Mingolla, E. (1994). Cortical dynamics of feature binding and reset: Control of visual persistence. Vision Research, 34, 1089-1104

Gregory, R. L. (1972). Cognitive contours. Nature, 238, 51-52.

von der Heydt, R., Peterhans, E. \& Baumgartner, G. (1984). Illusory contours and cortical neuron responses. Science, 224, 1260-1262.

Kanizsa, G. (1976). Subjective contours. Scientific American, 234, $48-52$.

Kellman, P. \& Loukides, M. (1987). Object perception and subjective contours. In Petry, S. \& Meyer, G. (Eds), The perception of illusory contours (pp. 151 162). New York: Springer.
Livingstone, M. S. \& Hubel, D. H. (1987). Psychophysical evidence for separate channels for the perception of form, color, movement, and depth. Journal of Neuroscience. 11, 3416-3468.

Nakayama, K. \& Shimojo, S. (1992). Experiencing and perceiving visual surfaces. Science, 257, 1357-1363.

Prazdny, K. (1985). On the nature of inducing forms generating perceptions of illusory contours. Perception \& Psychophysics, 37, 237-242.

Ramachandran, V. S. (1974). Studies in binocular vision. Ph.D. thesis, Trinity College, Cambridge University, Cambridge.

Ramachandran, V. S. (1985). Apparent motion of subjective surfaces Perception, 14, 127-134.

Ramachandran, V. S. (1986). Capture of stereopsis and apparent motion by illusory contours. Perception \& Psychophysics, 39 , 361-373.

Ramachandran, V. S. (1988). The perception of depth from shading. Scientific American, 269, 76-83.

Ramachandran, V. S. (1992). Visual perception: A biological perspective. In Grossberg, E. S. (Ed.), Neural networks in visual processing. Cambridge, Mass.: MIT Press.

Ramachandran, V. S., Tyler, C. W. \& Rogers-Ramachandran, D (1992). ARVO abstract. Investigative Ophthalmology and Visual Science (Suppl.), 35, 1511.

Reynolds, J. P. (1981). Perception of illusory contours as a function of processing time. Perception, 10, 107-115.

Rock, I. (1983). The logic of perception. Cambridge, Mass.: MIT Press.

Schumann, F. (1904). Einige Beobachtungen uber die Zusammenfassung von Gesichtdrucken zu Einheiten. Psychologische Studien, l, 1. 32.

Van Essen, D. C. (1985). Functional organization of primate visual cortex. In Peters, A. \& Jones, E. G. (Eds), Cerehral cortex. New York: Plenum Press.

Acknowledgements-We thank F. H. C. Crick, P. Churchland, and R. L. Gregory for stimulating discussions, and the ONR and AFOSR for support. 